Proceedings of the International Symposium on Physics of Materials (ISPMA 14), September 10-15, 2017, Prague

\title{
Variation in TiNi Alloy Properties on Room Temperature Holding
}

\author{
A. Sibirev*, S. Belyaev And N. Resnina \\ Saint-Petersburg State University, 7/9 Universitetskaya nab., St. Petersburg, 199034, Russia
}

\begin{abstract}
The aim of the present work was to investigate the influence of room temperature holding on martensitic transformations temperatures and resistivity in TiNi shape memory alloy, which was previously subjected to thermal cycling. The recovery in the martensitic transformation temperatures and resistivity was found during room temperature holding of the TiNi alloy that was subjected to preliminary thermal cycling. It was shown that the recovery in martensitic transformation temperatures and resistivity depend on the number of thermal cycles. It is assumed this was caused by the dependence of the intensity of recovery on the dislocation density. The larger the number of cycles, the higher the defect density and the more intensive relaxation occurred during holding. It was found that the dislocation structure that formed during deformation in martensite was more stable during room temperature holding then the structure which appeared during thermal cycling.
\end{abstract}

DOI: 10.12693/APhysPolA.134.671

PACS/topics: $61.72 . \mathrm{Cc}, 81.05 . \mathrm{Bx}, 81.30 . \mathrm{Kf}$

\section{Introduction}

TiNi-base shape memory alloys may be used as thermal mechanical actuators of repeating action due to the ability of these materials for reversible strain variation on cooling and heating under stress which is called the transformation plasticity and shape memory effects $[1,2]$. To provide stable working parameters of the actuators, the parameters of these effects should not change on repeating cooling and heating $[3,4]$. At the same time, it is well known that the thermal cycling of the TiNibased alloys leads to a decrease in temperatures of the strain variation $[1,5-7]$ and influences the values of the reversible strain in different ways according to the stress acting on cooling $[1,5,6]$.

The variation in the parameters of the transformation plasticity and shape memory effects on cooling and heating is caused by the influence of the thermal cycling on the characteristics of thermal elastic martensitic transformations which are the basis for the shape memory effects that are observed in the TiNi alloys $[1,5,6]$. It is believed that a decrease in transformation temperatures and a change in transformation sequence that are observed on thermal cycling of TiNi-based alloys in the stress-free state is due to multiplication and slip of dislocations during the formation of the martensite crystals on cooling [8-10]. For instance, in [9] it was shown that thermal cycling of the TiNi alloy led to an increase in dislocation density from $10^{12} \mathrm{~m}^{-2}$ to $5 \times 10^{14} \mathrm{~m}^{-2}$ during 100 cycles.

The dislocation slip during martensitic transformation is irreversible process, i.e. to recover the alloy structure and initial parameters of the martensitic transfor-

*corresponding author; e-mail: alekspb@list.ru mation it is necessary to anneal the alloy at high temperatures $[2,9]$. At the same time, there are some data that the partial recovery of the alloy structure may take place on holding at room temperature. In Ref. [11] it was observed that the martensitic transformation temperatures that were decreased during three thermal cycles of TiNi alloy might be partially recovered during two days holding at room temperature. It was shown that this phenomenon was caused by a redistribution in the dislocation structure. The opposite effect was found in [12] where the room temperature holding of $\mathrm{TiNi}$ alloy for $120 \mathrm{~h}$ was reported to lead to an additional decrease in transformation temperatures and it was attributed to the variation in the point defect concentration. It is hardly possible to find the nature of the discrepancy in the room temperature holding effect on the transformation temperatures observed in $[11,12]$ due to lack of experimental data. Nevertheless, the study of this phenomenon is very important because it may open the possibility for the recovery of the TiNi alloy structure and properties at ambient temperature without heating up to high temperature for annealing that is hardly suitable for working actuators. Thus, the aim of the present work is to study the influence of the room temperature holding on the recovery in martensitic transformation temperatures in TiNi alloy that was subjected to preliminary thermal cycling.

\section{Materials and methods}

The $\mathrm{Ti}_{50} \mathrm{Ni}_{50}$ alloy wire samples with a diameter of $0.5 \mathrm{~mm}$ and a length of $140 \mathrm{~mm}$ produced by MATEKSMA Ltd. (Moscow, Russia) were water quenched from $700^{\circ} \mathrm{C}$ and annealed at a temperature of $500^{\circ} \mathrm{C}$ for $1 \mathrm{~h}$. After annealing, the alloy underwent the martensitic transformation from the cubic $B 2$ phase to the monoclinic $B 19^{\prime}$ phase on cooling, and the $B 19^{\prime} \rightarrow B 2$ reverse transformation on heating. To increase dislocation density by thermal cycling the TiNi alloy sample was cooled 
and heated in a temperature range of $0{ }^{\circ} \mathrm{C} \div 140^{\circ} \mathrm{C}$ with a cooling/heating rate of $5^{\circ} \mathrm{C} / \mathrm{min}$. To study the room temperature holding influence on martensitic transformations the samples were held at the room temperature for $14 \mathrm{~h}$ after the 5 th and the 15 th thermal cycles and for $86 \mathrm{~h}$ after the 10th thermal cycle. To determine martensitic transformation temperatures the resistivity variation was measured by 4 -point method and the $\rho(T)$ curves were obtained for each thermal cycle. To estimate the variation in defect density on thermal cycling the variation in resistivity at constant temperatures of $20^{\circ} \mathrm{C}$ (in the martensite state) or $120^{\circ} \mathrm{C}$ (in the austenite state) was measured.

\section{Results}

The $\rho(T)$ curves obtained during thermal cycling were used to determine the temperatures of the phase transformations as intersection of tangent lines, and the dependences of temperatures on thermal cycle number are given in Fig. 1. It is seen that all transformation temperatures decrease during thermal cycling however, holdings of the samples at room temperature that take place after cooling in the 5th, 10th, and 15th thermal cycles lead to an increase in the $T_{R}, R_{p}, M_{f}$, and $A_{s}$ temperatures of the martensitic transformation measured during further thermal cycles (see open symbols in Fig. 1). The variation in $A_{f}$ temperature induced by holding is hardly visible. Thermal cycling of the samples after holding results in a decrease in the transformation temperatures to normal dependences (line) within a few further thermal cycles (Fig. 1). The deviations of the transformation temperatures $T_{R}, M_{f}$, and $A_{S}$ that were measured just after holding, from the normal dependences of the martensitic transformation temperatures on the thermal cycle number (line in Fig. 1) are given in Table I. It is seen that the variations of the forward transformation temperatures are greater than the reverse transformation temperatures. Moreover, it is found that the larger the

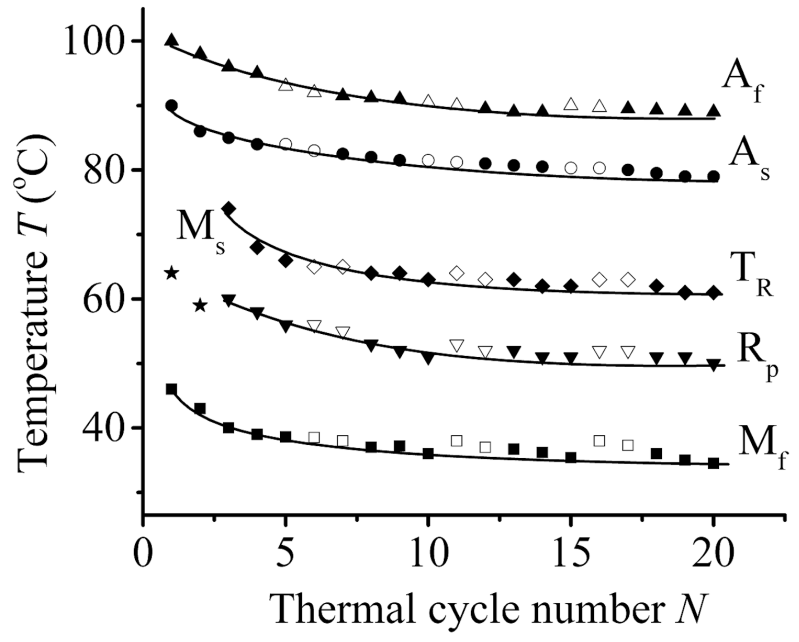

Fig. 1. Dependences of martensitic transformation temperatures on number of thermal cycles obtained during thermal cycling of the TiNi alloy. number of thermal cycles, the larger variation in transformation temperatures is observed after holding. An increase in holding time from 14 up to $86 \mathrm{~h}$ does not influence the transformation temperature variation.

According to $[10,13,14]$, the variation in transformation temperatures during thermal cycling is caused by the variation in defect density. It is verified by the data presented in Fig. 2 where an increase in resistivity during thermal cycling is shown. It is seen that thermal cycling leads to an increase in resistivity in the austenite and martensite states. If the room temperature holding influences the defect density then it should affect absolute value of the resistivity $[15,16]$. In Fig. 2 it is seen that

TABLE I

Variations in transformation temperatures and resistivity during room temperature holding of the $\mathrm{Ti}_{50} \mathrm{Ni}_{50}$ alloys. $N$ - number of thermal cycles where the holding is carried out, $t$ - holding duration.

\begin{tabular}{c|c|c|c|c|c|c|c}
\hline \hline$N$ & $t[\mathrm{~h}]$ & $\begin{array}{c}\Delta T_{R} \\
{\left[{ }^{\circ} \mathrm{C}\right]}\end{array}$ & $\begin{array}{c}\Delta M_{f} \\
{\left[{ }^{\circ} \mathrm{C}\right]}\end{array}$ & $\begin{array}{c}\Delta \rho_{20} \\
{[\%]}\end{array}$ & $\begin{array}{c}\Delta A_{s} \\
{\left[{ }^{\circ} \mathrm{C}\right]}\end{array}$ & $\begin{array}{c}\Delta A_{f} \\
{\left[{ }^{\circ} \mathrm{C}\right]}\end{array}$ & $\begin{array}{c}\Delta \rho_{120} \\
{[\%]}\end{array}$ \\
\hline \multicolumn{8}{c}{$140 \div 0{ }^{\circ} \mathrm{C}$} \\
\hline 5 & 14 & 1 & & & & -2 & 0 \\
10 & 86 & 1 & 2 & 0.34 & & -0.5 & 0.12 \\
15 & 14 & 1 & 2 & 0.41 & 1 & 0 & 0.28
\end{tabular}
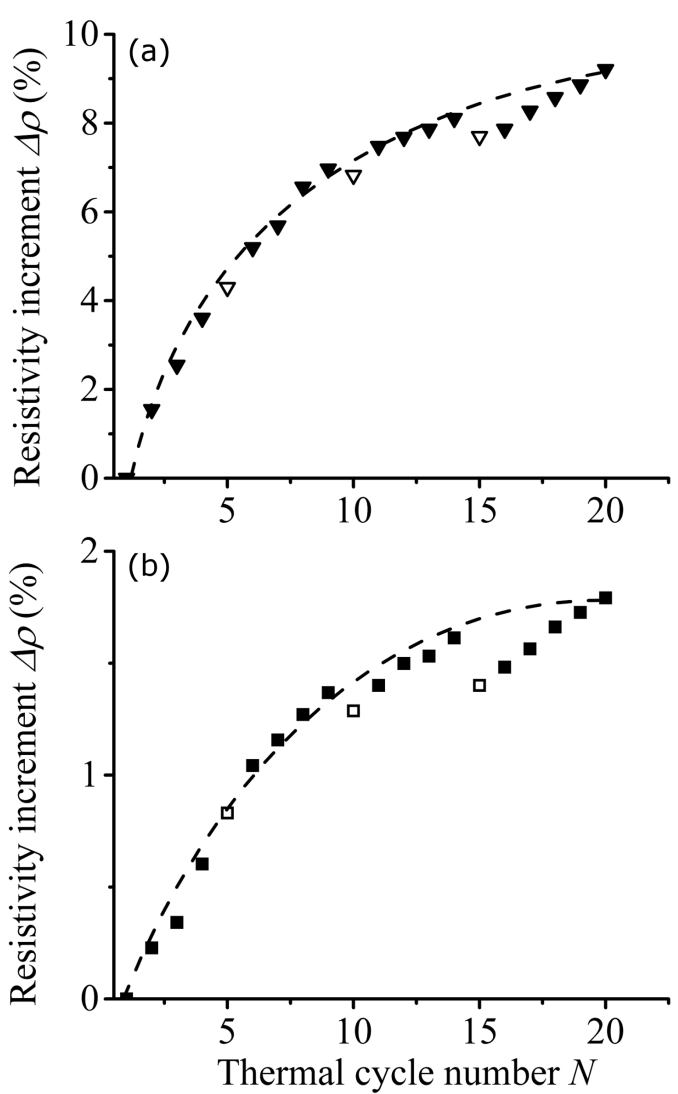

Fig. 2. Dependences of resistivity measured at 20 (a) or $120^{\circ} \mathrm{C}$ (b) on number of thermal cycles number obtained in TiNi alloy during thermal cycling. 
the resistivity measured in the cycle that has been performed just after holding of the sample at room temperature (open symbols in Fig. 2) is smaller than in previous cycle (solid symbols in Fig. 2). The differences between the resistivity increments observed in cycles performed just after holding and $\rho(N)$ curves (lines in Fig. 2) are given in Table I. It is found that the greater the number of thermal cycles, the more significant decrease in resistivity. Therefore, the variation in $\Delta \rho_{20}=-0.34 \%$ if room temperature holding occurs after the tenth cycle and $\Delta \rho_{20}=-0.41 \%$ if holding takes place after the 15 th cycle. A variation in holding duration hardly influences the resistivity change. Thus, the data presented in Table I show that room temperature holding of the TiNi alloy which has been preliminary subjected to thermal cycling leads to an increase in the martensitic transformations temperatures and a decrease in resistivity. Thus it confirms that the alloy structure is partially recovered during holding in a good agreement with [11].

The alloy structure recovery may be attributed to a decrease in defect density due to some relaxation process that takes place on room temperature holding. It is found that the intensity of structure recovery depends on the number of thermal cycles (Table I). Thus, it may be assumed that it is caused by an influence of the defect density on the relaxation process. The larger the number of thermal cycles, the higher the defect density and the more intensive relaxation occurs on holding. At the same time, defect density may be changed not only by the thermal cycling through the temperature range of the martensitic transformations, but also by active deformation in the martensite state. Moreover, it is evident that an increase in defect density during active deformation is larger than during thermal cycling hence, it may be expected that the relaxation would be more intensive during holding after active deformation of the TiNi alloy.

To study this assumption variation in resistivity was measured after deformation of annealed TiNi alloy samples up to 10,20 , and $30 \%$ at the room temperature at which the alloy was in martensite state and the resistivity variation at room temperature was measured for $11 \mathrm{~h}$. Figure 3 shows the resistivity vs. time dependences and it is seen that the resistivity variation is observed during holding. If the sample was deformed to $10 \%$ then the resistivity increases by $0.03 \%$ during room temperature holding while it decreases by $0.026 \%$ in the sample that was preliminary deformed to $20 \%$. The variation in resistivity was non-monotonic during holding of the sample that was deformed to $30 \%$ and after $11 \mathrm{~h}$ the value of the resistivity became close to the resistivity that was measured just after deformation. The comparison of the resistivity variation measured during room temperature holding after active deformation (Fig. 3) or the thermal cycling (Fig. 2a) showed that the relaxation that observed after thermal cycling was more intensive than after active deformation because the recovery in resistivity during holding after thermal cycling was ten times higher than after active deformation.

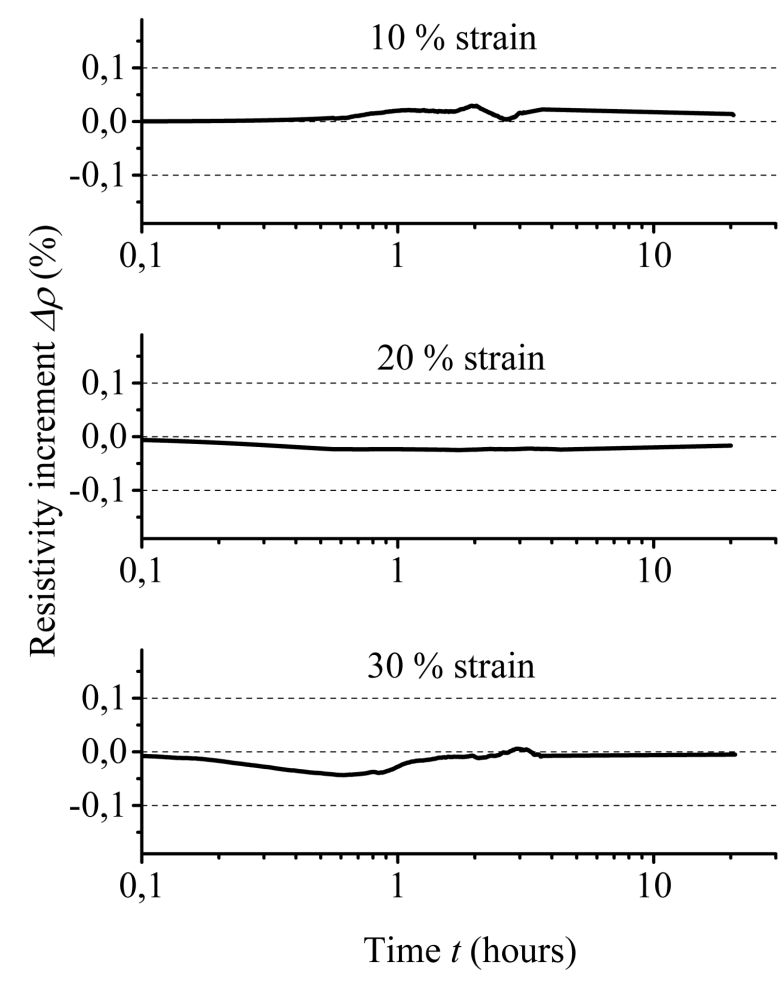

Fig. 3. Resistivity increment measured during room temperature holding of TiNi alloy that was preliminary deformed to 10,20 , and $30 \%$.

Therefore, the results of the study show that the dislocation structure that forms during deformation in martensite is more stable during room temperature holding than the structure which appeared during thermal cycling. It may be explained as follows. During deformation in martensite state the dislocations appear in the martensite phase, while during thermal cycling the dislocation form in the austenite phase [17] and then they are inherited by martensite structure [18]. The inherited dislocations have a large energy and it makes them unstable. That is why they are inclined to minimize their energy via redistribution or annihilation, and this leads to recovery of alloy structure on room temperature holding.

\section{Conclusions}

The results of the study may be summarised as follows:

1. The recovery in the martensitic transformation temperatures and resistivity is found during room temperature holding of the TiNi alloy that was subjected to preliminary thermal cycling.

2. The recovery in martensitic transformation temperatures and resistivity depends on the thermal cycle number. It is assumed this it is caused by the dependence of the intensity of recovery on the dislocation density. The larger the number of thermal cycles, the higher the defect density and the more intensive relaxation occurs on holding. 
3. The recovery in resistivity is studied after active deformation in martensite state and it is found that the dislocation structure that forms during deformation in martensite is more stable during room temperature holding that the structure which appeared during thermal cycling.

\section{Acknowledgments}

The study was funded by RFBR, according to the research project No. 16-31-60043 mol_a_dk.

\section{References}

[1] Y. Furuya, Y.C. Park, Nondestr. Test. Eval. 8-9, 541 (1992).

[2] K. Otsuka, X. Ren, Prog. Mater. Sci. 50, 511 (2005).

[3] J. Mohd Jani, M. Leary, A. Subic, M.A. Gibson, Mater. Des. 56, 1078 (2014).

[4] D. Stoeckel, Mater. Des. 11, 302 (1990).

[5] S. Belyaev, N. Resnina, A. Sibirev, J. Alloys Comp. 542, 37 (2012).

[6] S. Belyaev, N. Resnina, A. Sibirev, J. Mater. Eng. Perform. 23, 2339 (2014).
[7] M. Morin, F. Trivero, Mater. Sci. Eng. A 5093, 5 (1995).

[8] T. Simon, A. Kröger, C. Somsen, A. Dlouhy, G. Eggeler, Acta Mater. 58, 1850 (2010).

[9] A.R. Pelton, G.H. Huang, P. Moine, R. Sinclair, Mater. Sci. Eng. A 532, 130 (2012).

[10] S. Miyazaki, Y. Igo, K. Otsuka, Acta Metall. 34, 2045 (1986).

[11] M. Kaack, I. Delgadillo-Holtfort, T. Yohannes, J. Pelzl, Mater. Sci. Eng. A 378, 119 (2004).

[12] X. Wang, J. Van Humbeeck, B. Verlinden, S. Kustov, Scr. Mater. 113, 206 (2016).

[13] N. Resnina, S. Belyaev, J. Alloys Comp. 486, 304 (2009).

[14] W. Tang, R. Sandström, Mater. Des. 14, 103 (1993).

[15] Z.S. Basinski, J.S. Dugdale, A. Howie, Philos. Mag. 8, 1989 (1963).

[16] H. Matsumoto, J. Alloys Comp. 368, 182 (2004).

[17] P. Chowdhury, H. Sehitoglu, Prog. Mater. Sci. 85, 1 (2017).

[18] G.E. Brainin, V.A. Likhachev, Phys. Met. 4, 489 (1983). 